\title{
Innovation and VET student work placement
}

Steven Hodge and Ray Smith, Griffith University, Australia

Although vocational education and training (VET) is often sidelined in policy debates about innovation and how to promote it, some research and theory highlights ways the sector does contribute. VET can be, for example, positioned as an instrument of 'knowledge diffusion' and thereby an active element in so-called 'innovation systems'. But the role of work placement students in the overall contribution of VET to innovation has not been directly considered. This paper presents research into the possibility that VET placement students may indeed play such a role. This qualitative project involving an exploratory phase and four case studies indicates that placement students can, in some circumstances, play a discernible role in knowledge diffusion. The research also suggests that there are cases where students can play a direct role in small-scale innovation in the practice of organisations. At the same time, the research suggests employers, training provider staff and students themselves are influenced by stereotypes that may make it difficult to anticipate and acknowledge such innovation. With some work on stakeholder attitudes, it may be possible to tap into a hidden source of innovation.

Keywords: innovation, students, work placement, knowledge diffusion, practice innovation

\section{Introduction}

Innovation has become a buzzword in advanced economies as policy makers seek to exploit perceived national strengths for economic growth. The Organisation for Economic Cooperation and Development (OECD 2015) declares innovation as imperative, the foundation of the urgent new sources of growth needed across the world. "Innovative economies are more productive, more resilient, more adaptable to change and better able to support higher living standards" (OECD 2015, 11). Australia is one nation that has embraced innovation talk with its 'Ideas Boom' policy (Commonwealth of Australia 2015). The policy maps out sources of innovation that will be incentivised, including 'STEM' education and higher education. The contribution of education conceived here is two-fold: better preparing young people for intensive knowledge work involving scientific and technical reasoning, and research activity conducted by higher education institutions to be more oriented to business collaboration. It is to be noted that vocational education and training (VET) does not rate a mention in this policy. And this, despite the $\operatorname{OECD}(2015,12)$ citing "a skilled workforce that can generate new ideas and technologies, bring them to market, and implement them in the workplace" as the first of its listed five key features of a thriving innovation environment. What remains in the Australian policy is that the compulsory schooling sector is conceived as an incubator for the potentialities for possible future innovation, and the higher education sector is encouraged to reconceptualise the way it does its research to produce more tangible economic results.

This paper reports on a qualitative, exploratory investigation into a possible alternative contribution education may make to innovation, formally reported in Hodge, Smith, Field and Flynn (2017a). Specifically, the study focused upon the possible contribution of VET, despite official silence on the role it might play in innovation. The alternative here is that the student work placement process - in this case work experience undertaken as part of a formal program - might serve as a catalyst for reflection and improvement in the host organisation. The paper provides an overview of the 
research and highlights two types of contribution that emerged from the evidence gathered. The bulk of the evidence derives from four case studies of host organisation student placement practices. Our analysis indicates that across these cases there were two distinctive contributions to change and improvement in organisations: knowledge diffusion and practice innovation. It should be noted that neither of these types of contribution fits comfortably within Australia's official definition of innovation (which stresses commercially desirable novelty) leading us to conclude that in terms of this commercial definition, student placement probably does not contribute. But we also suggest that a broader view of innovation can be justified in which perspective the student placement process has more potential. The next section addresses existing theory and research, including the matter of definitions, before entering into details of the project and its findings.

\section{Innovation and student placement: existing theory and research}

An extensive literature has sprung up around the idea of innovation. Emerging in the early $20^{\text {th }}$ Century, the concept of 'innovation' was linked with economic productivity and was seen as emanating from the work of specialised individuals and teams (Schumpeter 1934, Rice 2011). 'Research and development' (R\&D) units concentrated knowledge and problem-solving prowess to drive innovation, and such units remain a component in organisations and systems (Raymond and St Pierre 2010). Consistent with this specialised and economic take on innovation, Australia's official definition of innovation emphasises 'the development or introduction of new or significantly improved goods, services, processes or methods' (Australian Bureau of Statistics (ABS) 2016). This definition derives from the Oslo Manual (OECD 2005) and underpins the annually conducted Business Characteristics Survey (BCS) that addresses four key types of innovation - i) goods and services produced and organisations' ii) operational processes, iii) managerial processes and iv) marketing methods. The primary benefit of innovation reported in the BCS is increased revenue. The ABS innovation definition is business oriented. Its focus is data related to the enhanced profitability generated by organisations when they adopt new and improved business practices. But this business and commercially-focused definition has been augmented by shifts in how the nature and sources of innovation have come to be conceived. These shifts have given rise to broader, less 'bottom line' understandings of innovation and what constitutes the new and improved that qualifies as evidence of innovation.

In terms of sources of innovation, there has been both a recognition of the contextual nature of innovation and of complementary top-down (management driven) and bottom-up (worker driven) innovation within organisations. Nelson and Rosenberg (1993) described national 'innovation systems' that are supposed to create a matrix for innovation at the individual organisational scale. Such systems can be described and potentially enhanced to promote innovation across multiple organisations. In later work, Laursen and Salter (2005) draw attention to the contribution of organisational 'openness' - embracing interaction among suppliers, users and institutions - as a key element in innovation systems. The flow of ideas among parties to innovation systems has been described as 'knowledge diffusion' (Ernst and Kim, 2002). Such a flow of knowledge is considered a catalyst for the introduction of the new or significantly improved. The complementary notion of 'absorptive capacity' (Lazonick 2005) points to the fact that although flows of knowledge may be available to an organisation, they must be able to actively engage with and deploy such knowledge. Alongside this acknowledgement of context in the innovation mix is the identification of a distinct driver of innovation coming from workers. Hoyrup (2012) argued that when conditions in an 
organisation favour worker autonomy, information sharing and individual responsibility, there is scope for 'bottom up' employee driven innovation. Further to this, Smith (2017) argues that the learning and transformation practices that typically characterise work can make it, even at its most routine, an innovation practice. Work itself, more than individual workers, drives innovation. The expanded conceptualisation of sources of innovation here crosses with broadened notions of what it is to innovate. Ellström (2010), for example, suggests that there is a mode of innovation he calls 'practice innovation' which draws attention to a more nuanced way in which everyday work activity can lead to and be characterised by improvement that can have economic but also well-being effects that are less dramatic and measurable than the prototypes of R\&D departments. Thus bottom up innovation can be considered in relation to products or practices - a source of innovation in the narrower, commercial sense - or the improvement and creation of the practices that sustain our working lives and enhance our contributions to the organisations in which we work, and the occupational practices enacted.

The role of education broadly and vocational education and training (VET) more specifically in innovation is difficult to clarify. There is the overarching view that education and training contribute to human capital development (Mincer 1958, Becker 1964, OECD 2012). Human capital is that which adult economic agents of all kinds deploy when they work but also when they innovate. Education thus has an indirect, albeit foundational, role in enabling innovation. Post-school education, being closer to formation of capabilities for labour markets, has been scrutinised for its contribution to innovation. Higher education and universities are considered to have a direct impact on innovation, positioned as they are to generate and introduce new knowledge to economies (Lundvall, 2008). This view appears to be accepted by policy makers. In recent innovation policy documents, the Australian government (as an example), acknowledges higher education as playing a key role in driving innovation. Incentives announced in the policy are distributed across STEM and higher education and business activities, especially those that involve higher education-business partnerships (Commonwealth of Australia 2015).

What does VET, as a large post-school education sector, contribute to innovation? The Australian government innovation policy does not mention VET. However, a string of research projects has indicated ways that VET might contribute to innovation. A relatively early position was articulated by Dawe (2004) who emphasised the link between VET and continuous improvement, a process thought to engender innovation. Curtin and Stanwick (2011) differentiated three ways VET can contribute: through development of technical skill in the workforce, the development of core or generic competencies such as teamwork and problem-solving, and as a component in the national innovation system. Research in regional and rural Australia indicated VET has the capacity to enhance innovation through the supply of skilled workers (Pickersgill and Edwards 2005). Toner (2007) argued that VET helps to drive innovation through a process he calls 'technology diffusion'. The related notion of knowledge diffusion, introduced above, has also been linked to VET activity in research by Dalitz, Toner and Turpin (2011).

In each of these studies of VET's relationship with innovation it is the key function of education in technical and generic skills that is operative. In Australian post-compulsory education, VET is officially positioned as a skills development sector with primary responsibility for skills defined in the first six of ten levels within the Australian Qualifications Framework (AQF Council 2013). Higher education generally focuses on the 'higher' level qualifications (AQF levels 6-10). At the lower end of 
the AQF spectrum, VET delivers entry-level Certificate I, II and III qualifications through to Certificate IV, Diploma and Advanced Diploma programs that stress advanced technical skills, autonomy, responsibility and supervisory skills. In the case studies to follow, students were all enrolled in either Certificate III or Diploma programs. In general, and as illustrated by these examples of qualification outcomes, VET is a means of technology and knowledge diffusion and thus in principle a necessary component in the national innovation system. Graduates of VET programs, and to a certain extent other activities of VET educators and providers, are the vehicle for diffusion. In these studies the potential of VET student work placement to convey new knowledge and skills into organisations was not considered. VET knowledge and skills do not only enter organisations through graduate and provider activity. To date, there has been little research to investigate possible VET student placement contribution. Indeed, there is only limited literature on VET student placement as such. The research that is available has focused on the scope for placement to enhance learning (e.g. Billett 2009, Guile and Griffiths 2001) or its role in the development of VET provider and industry partnerships (e.g. Guthrie et al. 2014). This research confirms that it is a good idea educationally to complement institutional provision of VET with opportunities for practice in functioning workplaces or that placement has the potential to be more than a burden on providers and host businesses, but can be the occasion for better partnerships.

Two studies, however, have connected VET student placement with workplace change. In one, learning outcomes for information technology placement students were acknowledged alongside impacts on industry partner learning (Armatas and Papadopoulos 2013). In this research the role of placement students themselves in such diffusion of learning was not examined. In a more recent study, Zulch et al. (2016) remarked the positive impact of placement students from an allied health assistant program on the wellbeing of aged care residents with whom the students worked. Studies of higher education placement or internship also hint at changes brought by students. In a UK study, Piterou and Birch $(2014,76)$ found that internships 'contribute to the development of absorptive capacity of small firms through the use of students' skills'. Research by Gibson and Naquin (2011) in Portugal acknowledge the role of students on internships in the commercialisation of technology. What these four studies suggest is that students on work placement may serve as a catalyst for improvement and possibly innovation. The project presented in this paper was devoted to the question of VET student placement contribution to innovation in host organisations. Building on the suggestions of these four studies, and taking into account perspectives on how VET might contribute to innovation, the project aimed to clarify whether and how VET student placement contributes to innovation.

\section{Conducting the enquiry}

The research was conducted in two phases: an exploratory phase and a formal case study phase. Given the relative dearth of literature pertaining to the research question, the project commenced with an open, exploratory approach to data collection. In this phase 'Cases' were loosely constructed around VET program areas known to mandate student placement as part of their formal studies. These program areas were community services, hospitality, carpentry, metal fabrication and electrical services. For each program area, interviews were conducted with host employer staff, training provider staff and students. Some 41 interviews were undertaken for this exploratory phase, 13 host staff, 11 provider staff and 17 students. These program cases were ones that could be conveniently accessed by the researchers and included those offered by both public and private VET 
providers. The interview questions (see Hodge, Smith, Field and Flynn 2017b for schedules) sought opinions about the potential of student placement to contribute to innovation and any examples of such contributions. Care was taken in the writing of the interview questions to use terms like 'improvements' and 'changes' as well as 'innovation'. Public debate in Australia was awash with innovation language at the time of the research, and it seemed more likely the interviews would elicit useful data if less topical words were used to frame the interview conversations. But the interview schedules included direct questions about innovation that revealed surprisingly diverse perspectives on the part of participants (Hodge et al. 2017b).

The first phase of the research alerted us to a number of considerations. First, people were not used to connecting placement students with potential to make improvements. Some host staff, provider staff and students seemed to reject the possibility of such connection. As a host organisation staff member answered the question whether students could contribute to innovation, 'I don't think so. Not innovative. I mean, the innovation comes from the leaders of the company. You've got to teach them [the students] everything.' Such was the view, or stereotype, about the potential for student contribution. But other participants, when prompted, could recall examples of positive organisational change and instances of individual student contributions. Students themselves were reserved about making suggestions to host staff, but were also able to call to mind examples of seeing improvements and sometimes of communicating and enacting them. Importantly, the data indicated that participants held quite diverse views about what innovation is and how it arises in work.

The second phase of the research was a more formal multiple case study design with host employer organisations constituting each 'case'. A survey was designed to help identify cases. From the exploratory research we judged that employers who expressed openness to the proposition that student placement could contribute to improvement would offer more germane sites to investigate the question. The exploratory phase also suggested larger employers and employers with more developed systems for supporting placement might make for more fruitful sites. The survey (which can be accessed at Hodge et al. 2017b) was also designed with a view to possible large-scale surveying, with items that sought broad information about student placement practices. However, in the event a relatively small number of host organisations were able to be contacted (approximately 180). Of these, 36 completed the survey and 17 of them agreed to be contacted for follow-up research. In selecting four host organisations for case sites, a cross-section of industries was sought. Evidence of an open attitude to the possible contribution of student placement and organisational scale were also key criteria for selection. The four case studies selected were in the industries of hospitality, community services, early childhood education and care, and health. To build each case, semi-structured interviews were conducted with students, host leadership and operational staff, and training provider staff. The latter interviews proved to shed little light on the cases. Provider staff, at least for training in the qualifications represented in this research, had relatively little specific insight into practice at the host sites. We have left their data out of this paper, focusing instead on the students and host staff whose rich everyday interactions constituted the background against which student placement contributions to improvement might be discerned. Leadership views were often removed from this level of practice, but we interpreted their data as helping to establish the 'tone' of the host site, giving us an idea of the overall texture of affordances within which student placement played out. Host organisation staff and placement students comprised 69 semistructured interviews across the four case organisations. All interviews were approximately $30-60$ 
minutes, transcribed and de-identified. The analysis and findings of this transcript data, with illustrative excerpts, follows. Brief summaries of the cases are presented before an analysis and discussion of two types of innovation we think may be associated with student placement.

\section{Innovation and the placement experience}

It must be noted that the following four case studies are service providers (one of which is not-forprofit) and that they may be said to represent organisations at different points along a continuum of student placement innovation recognition and acknowledgement. That is, in terms of the kinds of new and improved practises that could be attributed to students' as sources of information and contributors to better ways of doing things, the first case study reveals no evidence of such attribution, the second and third a little and progressively more, through to the fourth case study that reveals some clear evidence of students making a positive difference to organisational practices. The suggestion that these attributions may be evidence of innovation is taken up in the discussion that follows the four case study outlines.

\section{Hospitality - Catering}

This host organisation is a provider of catering services based at a large convention centre. The organisation caters for medium and large events, up to thousands of people. Students from Certificate III in Commercial Cookery, Certificate III in Hospitality and Diploma of Hospitality Management programs are placed at the organisation. For this case, 13 staff were interviewed (including managers, chefs and casual staff) and 10 students. Systematic integration of student placement into the organisation's operations was relatively new, initiated by a new training manager who had previously worked in the VET sector. Senior staff were positive about the benefits of the arrangements to the students and to the organisation. These staff recognised the value for the students of experience in a large, commercially successful organisation. At the same time, student placement enhanced organisational agility. With highly varied event scales, the organisation needed access to a large, flexible workforce to respond. Placement students had come to be seen as essential to the agility of the organisation.

However, examples of contribution to improvement or innovation were not identified by staff or students. Perhaps, the fact that catering for large events is, in part, an exercise in uniform provision of everything from cocktails through to customer service accounts for the limited opportunity to contribute to innovation. As one staff member put it, 'No it's down to, l'd say perfection almost', drawing attention to the point that the goal of the organisation is consistent standards through strict adherence to proven operational systems. A supervisor said,

I wouldn't say [the students] improved the processes, but there's some of them that have just shone from day one. It's like, 'Yep, so as soon as you're finished your studies, we want you on board if you want to stay.'

The possibility of student-driven improvement was acknowledged by one supervisor who spoke about how questions regarding work posed by students could open the possibility of reviewing processes:

I think sometimes them asking questions might make us stop and question why we do some things, which can sometimes then lead to us going, 'Well yeah, that maybe isn't the only way 
to do something,' and we'll look at reviewing another alternate way. So it's just sometimes that fresh set of eyes that might make us think, 'Well why?' Then we'll try to search for the answer why or explain why we do that. But if someone did have an alternate way of doing something, we would give it a go.

But staff were not able to present examples where students were in some way responsible for improvements. The students were also unable to supply examples of improvement initiated by themselves or other students. Rather, contribution was framed in terms of excelling in work attitude and customer service. As one student explained,

I feel like I've made a big change around this place just with my work ethic and just keeping a smile on my face and just always being willing to do whatever needs to be done - at the very beginning when I started working here it was just - I don't know, things were a bit messy. I was always having to clean up after people. People just leaving stuff around.

At this organisation students are clearly an important part of operations and high standards of service and presentation are the criteria for outstanding contribution. Although some staff were open to the possibility of student contribution to improvement, in practice the contribution was to the well-known goals of the organisation. This case does not indicate that innovation was introduced by placement students, whether innovation is understood in the commercial sense or in the sense of practice innovation. Knowledge diffusion was not in evidence, either.

\section{Community services - Support Unit}

This host could be considered an organisation within an organisation. The Support Unit is set in a large secondary school and provides specialist services to disabled students and those with "learning disorders'. Specialist staff run the unit, while teachers from the secondary school visit to run classes based on the mainstream curriculum. Students from Certificate III in Education Support, Diploma of Community Services and Diploma of Youth Work programs undertake placements in the unit. The fact that students preparing for community service and youth work roles are placed at the unit points to its broader function to establish ties with community to bring in extra layers of support for the clients. Eighteen unit staff (leadership, administration, teacher's aides and teachers) were interviewed along with nine placement students across the three VET programs mentioned. Leadership described several benefits of placement including giving teachers the opportunity to be more innovative in their delivery. At this level of the organisation, student placement was seen as contributing indirectly to innovation by enabling staff to be more 'creative'.

Operational staff drew attention to another form of innovation that they linked with student placement. One of the staff, a teacher's aide, said,

I'll watch them and I'll go now how, what can I use? What am I looking at? What can I use in my work? What do I need to brush up? Because we're always looking for a way to do a better job ... I pick up a lot from the students that come in here ... they'll have different communication techniques and I'll look at how they're communicating with my young people and see how can I modify my behaviour?

Making a similar point, another aide explained that, 
You sit back and observe and you think, 'Oh, I haven't seen him [a high-needs client] react like that before.' Maybe that's something you might take on because that child reacted really well to that. Or it could be a negative reaction and you think, 'Oh well, I'm never doing that!'

An example of this kind of contribution was offered by a third aide:

When she [the placement student] came in I watched her and in a way I got a little bit jealous. I thought, hold on, those kids don't normally accept anyone. Then I - we were talking, and I said, what did you do? ... I thought, I've not done that [before].

These and other accounts alert us to a type of improvement in this organisation that involves identifying effective ways of working with particular clients. Exploring the nature of this improvement in interviews, the word 'mystery' came up to describe certain high-needs clients. Unit staff were in part engaged in a continual investigation into the best way to work with individuals who were unable to directly communicate what would and would not be effective. Placement students could bring a fresh repertoire of modes of interaction that were specifically observed by staff curious to see if the 'mystery' constituted by some of their challenging clients would be unravelled thereby contributing to improved practice.

For their part, most of the placement students did not express awareness they could contribute in this way. Many presented their contribution simply in terms of doing their best to follow instructions. Younger placement students in particular spoke in this way. Older students seemed more confident to talk about possible improvements, although these suggestions were not necessarily communicated to unit staff. A 36-year-old student said,

I definitely see improvements ... even though they're fantastic teacher aides, but they're a lot older. They're not in with the new-age way of doing things, but because they are older you respect them ... You don't try and say, 'Hey, look, new research has come in to say this is a better way of doing things.'

A 50-year-old student described a change that she implemented. She said that she observed the support staff acting as 'scribes' to the high needs clients, effectively doing the school work for them. The student explained her own approach,

I felt like I could just sit with this student for a little while, try and encourage them to write themselves and talk through it. I always say to them you tell me what you're doing, teach me what you're doing. It encourages them to gain the knowledge of what they're doing.

This student did not explicitly promote this approach to staff, but rather adopted it. We did not discover whether any of the staff had observed the student's practice.

In the Support Unit case we see a focus on the persistent challenges of everyday practice. Without design or even particular awareness on the part of different groups, the placement students brought practices that might or might not have improved the situation for individual clients. Staff would observe the placement students, noting and adopting more effective ways of working. Students were likewise observing staff, learning, making judgements, in some case noting but not necessarily communicating feedback and suggestions for improvement. It seemed the staff were not 
communicating to students that they were watching for the effectiveness of new ways of interacting. Yet the situation of some of the young people served by the unit improved. The puzzle they presented to staff could in some instances be solved by placement students. The improvements evident here are to the lives of individual clients and enacted at the level of staff practice. There are examples here of placement students contributing to practice innovation by modelling improved ways of interacting with clients that are appraised and adopted by staff. Staff also mentioned that up-to-date industry-relevant knowledge was introduced by students, such as legislative changes. Knowledge diffusion is thus also a contribution of the placement process at this site.

\section{Early childhood education - Childcare Centre}

The Childcare Centre is a metropolitan service educating and caring for pre-school age children (0-5 years) with 13 permanent educator staff along with administrators. Casual staff were also engaged to give the centre flexibility in the face of fluctuating demands for the service. The centre operates in a regulated environment, with fixed ratios of staff to children and staff qualification benchmarks. At the time of the research, the centre placed VET students studying Certificate III and Diploma Early Childhood Education and Care programs run by a large public VET provider. Each working day the centre hosted at least one placement student. This case was built up from interviews with 10 individuals: four staff, two trainers and four students.

Centre leadership saw clear value in the placement process, drawing attention to the legacy of past placement students in improvements to the centre grounds and gardens, the introduction of compost bins and recycling policies, the healthy food practices to which parents were now committed. An assistant manager commented that,

mostly they [students] have new and fresh ideas, the theory is there and they're wanting to put that into practice and we get to watch them go from being sometimes shy to confident educators leading group activities and doing all sorts of new things with the children ... we need students to be doing that. We can get so stuck in our ways, dealing with the day-to-day care of the children so we try to be open and encouraging of the students. We're all learning together.

One of the centre teachers expressed a similar point,

I've got a [placement] student like that at the moment and I'm learning from her, her ideas are amazing ... but all the students we get are quite good; they've all got something to contribute. They make you appreciate that, when you're so busy, bogged down in the paper work and stuff like that, you need to refresh.

Another teacher put it this way:

And they [the placement students] help me - bringing new ideas, making suggestions, picking up on things and taking them to the next level ... and the children grab hold of it, the parents love it.

In terms of student views on their contributions to improvement at the centre, the four participants shared the idea that to succeed as students in this environment, they had to be 'innovative'. The institution of a new regulatory framework in the sector meant that there was significant scope to 
identify improvements and directly contribute to their enactment. Some have already been described: implementing a recycling policy with all the equipment, procedures, communication and development such implementation entails. The students described improvements at the level of interactions with individual children (learning about their interests and how to engage them) and at the level of improvements to the learning spaces. Many of these improvements were facilitated through explicit communication and collaboration with staff, other improvements were initiated and implemented individually.

What this small case suggests is that student placement can be a source of considerable, enduring change and improvement, impacting on the day to day operations of an organisation. The students brought new ideas and they observed ways to improve the centre. An important element in this practical impact appeared to be the acknowledgement of and openness to the potential of placement students to make tangible contributions to the organisation. We can interpret the contribution of placement students in terms of practice innovation - staff value and adopt new ways of working - and knowledge diffusion - knowledge of changes to the sector studied in VET courses were transferred to the organisation by the placement students.

\section{Health - Suburban Hospital}

The last case we present is based on a suburban hospital that hosted students from a Diploma of Nursing program. A large public provider owned the program, although it was conducted primarily within the hospital, with hospital educators taking a central role in teaching and assessment. For the majority of the students, all 380 hours of mandated practicum was undertaken within this one hospital system. This practice is part of an organisational model that views the Diploma and student placement as an integral component of the recruitment and workforce development system. The hospital group employs most of the graduates from this particular qualification. This case was built from 11 interviews, six with staff (leadership and operational) and five students who had all just completed their final placement and who could thus provide an overview of their whole placement experience.

All of the participants - staff and students - acknowledged a function of the placement process to disseminate up-to-date techniques, knowledge and hospital policy. Describing this function, a senior staff member said that the students,

might come in and say, 'Look, we've been taught at [the provider] that there's a different way to do an injection now as per best practice', and our hospitals haven't come around to that new information as yet, so [the students] bring that into the hospitals.

Another explained that,

I think [the students] make the [nursing] staff more accountable. So I think that the staff actually sometimes will take a step back [and think], 'Maybe actually my practice ... I need to pick up my practice a bit', because they might have got into bad habits.

An operational staff member echoed these views, drawing attention to some of the tensions that might be expected: 
... [the students] often challenge things that older, more experienced nurses do and take for granted ... a simple example is nurses who've graduated more than a few years ago [and who] will, as standard, alcohol-wipe every injection site before they do it. That's actually not the best practice.... Often [the students will] be gutsy enough to question the nurses on the ward, and so we've had to make some adjustments and offer some education [to the existing staff].

For their part, the students recalled and could each articulate instances of contributing to change. Invited to reflect on differences between what they are taught and what they see in practice, one student said,

... we certainly have things that we did differently and we'd have to say to them, 'Look, we've been asked to do it this way', and we would show them, and some of them took that on board and said, 'Yeah, that's a really great way of doing it'. Some of them rolled their eyes at you. You just had different responses, depending on the nurse, but I think that just comes down to - because nursing is such a progressive industry, it's always changing.

Another described a new swabbing technique for injection sites that was being introduced to the hospital which involved three rather than one swabs. The placement students were taught this new method and were obliged to use it regardless of the established practice:

So when you're on the wards and you're doing that ... you would say: 'Look I have to swab this three times', and they're like, 'What?' and it's like 'Well this is what they're trying to bring into the hospital. This is what they're telling us now to do'.

It may be helpful to point out here that these students are inculcated with a professional practice principle that each nurse is responsible for verifying their actions. That is, in the legal framework of healthcare in Australia, nurses are held individually responsible for their actions; in cases of poor practice they cannot plead that they were over-ruled by a more senior staff member. Hence even the student nurses are obliged to declare their knowledge and challenge decisions and actions they see as contrary to policy or best-practice. This background information helps us to understand the confidence of these placement students to introduce different practices into the workplace, as well as the contrast between the stance of these students, and the less confident approach of students in other cases. It should be observed also that all of the students in this case were diploma-level students, indicating that we can associate higher levels of VET study with knowledge-sharing practices. The Suburban Hospital case presents us with clear examples of knowledge diffusion where knowledge of new techniques and updated policy are introduced to the workplace by placement students. On the other hand, practice innovation was not discerned. This finding makes sense in the context of a highly regulated, rigorously methodical environment in which novelty in practice would carry unacceptable risk.

\section{Discussion}

Bearing in mind the limitation that the case studies were all in service sector organisations, some tentative conclusions can be drawn with respect to the research question. With reference to the definition of innovation as 'new or significantly improved products, services, processes or methods' (ABS 2016), we cannot unequivocally assert that the student placement process contributes to 
innovation. Taking the host organisations as services, no new or significant improvements to services can be cited that placement students introduced. The services themselves remained essentially what they were before the advent of placement students. However, if the definition of innovation is extended or reconceptualised, and a more nuanced approach is taken to what constitutes 'improvement' in organisations, then we would be more confident about the possibility that the student placement process can contribute. With reference to some of the more nuanced conceptualisations of innovation surveyed earlier in the review section, we suggest that placement students may contribute to innovation in two ways.

First, in both the Support Unit and Childcare Centre cases, there was evidence of placement students contributing to improvement in the day-to-day practices of organisation staff. In the Support Unit, one of the obstacles to effective functioning of the organisation was the occasional want of customised practices for managing individual clients. The placement students, bringing unique knowledge and dispositions to bear, could overcome some of the seeming intractable challenges posed by high-need clients. Sometimes this knowledge was derived or shaped by VET curriculum. In some instances, it was personal experience that was key. Students were not necessarily aware of the role they played in unlocking the mystery of some of the clients. Staff would notice, select and adopt new practices that proved effective and register those that seemed ineffective and to be avoided in future. We note that such practices were introduced by both Certificate III- and Diploma-level students. The kinds of improvements indicated here are in the scope of Ellström's concept of 'practice innovation'. Placement students in the childcare centre could also be seen as contributing to improved practices. Here again, the day-to-day practices of the host organisation staff were altered through placement student activity. In both of these cases, 'improvement' was at the level of well-being of individuals and groups who were otherwise satisfactorily serviced by the organisation. We suspect it is important to acknowledge that new or significantly improved practices may be something that occurs at the 'micro' level of a single client or child. Should we equate a breakthrough in the daily well-being of a high-needs client with the breakthrough represented by a new technology that will be enjoyed by a large number of people? We think that it is worth at least debating whether innovation policy should encompass practice innovation. Such a debate would need to grapple with the idea that innovation may also amount to 'improvement' at the micro level to the lives of individuals.

Second, with respect to the Suburban Hospital and to a lesser extent, the Support Unit and Childcare Centre cases, the student placement process was one way that new knowledge was conveyed into the workplace. Whether it was new hospital policy specific to the workplaces that hosted the students, or revised techniques that constituted new benchmarks in the medical industry, students were at the cutting edge of the introduction of improvement. At the Childcare Centre and Support Unit, there was evidence of placement students introducing up-to-date sector-specific knowledge into the organisations. In these three cases it should be noted it was the Diploma-level students who were most obviously engaged in articulating such knowledge. In the innovation literature surveyed above, knowledge diffusion is regarded as an essential element in innovation systems. Specifically, VET has been positioned as a vehicle of knowledge diffusion (Dalitz, Toner and Turpin 2011), although that research did not acknowledge the potential role of VET student placement in such diffusion. The Suburban Hospital case, and also to some extent the Childcare Centre and Support Unit cases, produced evidence that knowledge, represented in higher-level VET curricula (itself 
ideally based on current industry standards) was diffused to host organisations through placement students. A second way in which student placement may contribute to innovation is thus indicated.

The ways the student placement process can contribute to innovation - through knowledge diffusion and practice innovation - and what we observed about how staff and organisations respond, suggest practical strategies for enhancing the impact of VET on innovation. On the provider side, there could be discussion with students about what innovation can involve, including the concepts of practice innovation and knowledge diffusion, and ways placement students can contribute. Providers and students could identify possible processes and projects for facilitating innovation. Assessment tasks, for instance, could explicitly emphasise practice innovation and/or knowledge diffusion. On the host side, the declared willingness of most employers we interviewed to accept suggestions for improvement from students along with the evident practice of staff in learning from students could be leveraged to create an explicit innovation strategy. Host organisations could make clear to placement students that they welcome ideas for improvement, while staff interacting with students could spend time as a group reflecting on what students have brought to their individual attention so knowledge and improvements to practice can be acknowledged and diffused more systematically through organisations. These basic suggestions present possible ways in which the contribution of placement students to innovation can be more adequately realised.

\section{Conclusion}

Our research did not find clear evidence that VET student placement could directly contribute to new or significantly new products, services, methods or processes. In other words, student placement did not contribute to innovation (according to a widely accepted definition in Australia) nor does it support the urgent new growth the OECD (2015) declares as imperative. Perhaps this is an unremarkable finding adding weight to common sense about learning and learners. If VET students, like any students, are novices in an occupational area, why would we expect to find they contribute to innovation? This view was expressed by some employers and trainers interviewed for this research: learners are novices but you require expertise in an area to innovate, therefore learners cannot contribute to innovation. This view is implicit in theory of innovation, especially in early theory that it is the genius of highly learned individuals which drives the new and significantly improved. Modern research and development units, teams and programs extend this thinking about the necessity of high-level expertise and sanctioned capacity to enact change.

The review section earlier drew attention to alternative perspectives on innovation. Against the view that the solitary genius or sequestered elite unit is the only way to conceptualise the emergence of innovation are notions of 'bottom up' innovation and of practice innovation for example. Then there are conceptualisations of innovation that emphasise the importance of context. 'Innovation systems', in this thinking, constitute the necessary setting of innovation. Bottom up innovation recognises the insight and ingenuity of workers and their potential to contribute to innovation. The concept of practice innovation nuances the basic idea of innovation and what can be innovated. Our research suggests that student placement can play a part in innovation when the latter is understood in this subtler way. The students placed in early learning and client support settings could bring improvement, at least to the lives of young and high-needs people. The improvement was to practices that form the immediate context of service. In the hospital case, students were 
clearly instrumental to the diffusion of knowledge. If knowledge diffusion is a vital precursor to innovation, then here, too, student placement has a distinctive role to play.

The research indicates there is relatively unrecognised and untapped potential for student placement to contribute to innovation. In economies that promote innovation as a goal worth understanding and resourcing, the recognition that VET student placement can contribute should be an important insight and one worth further investigation and development. Yet we cannot underestimate the influence of the assumption that learners, by definition, cannot play such a role. It might be that from policy makers, through to employers, training providers and the students themselves, disempowering assumptions need to be challenged at the same time as the potential for contribution to innovation is acknowledged and leveraged. The research thus leads us to question the wisdom of adherence to the commercial and elite perspective on innovation espoused by Australian policy makers while at the same time challenge simplistic views of VET students as inherently deficient in the knowledge and capacity to contribute to improvement.

The research reported here was exploratory. Given that, in the light of a more differentiated understanding of innovation, placement students may be able to contribute, it would be worthwhile to pursue further research on the nature of this contribution and conditions that promote it. Indications from the present research suggest some questions that could guide future studies. From the VET side, what is it about the background of students, or pedagogy, curriculum and assessment, or level of study, or preparation for placement, or the provider-host relationship that can foster student contribution to innovation? From the host organisation side, what is it about the way work is organised, or expectations of staff, or the influence of differences among industries and occupations that impact on student contribution? In an environment where there is high-level interest in promoting innovation, it makes sense to explore ways to tap into what may be a new source.

\section{References}

Australian Bureau of Statistics (ABS). 2016. Innovation in Australian business 2014-15. (8158.0). http://www.abs.gov.au/ausstats/abs@.nsf/mf/8158.0

Armatas, C., and T. Papadopoulos. 2013. "Approaches to work-integrated learning and engaging industry in vocational ICT courses: Evaluation of an Australian pilot program." International Journal of Training Research 11, no. 1: 56-68.

Becker, G. S. 1964. Human capital theory. New York: Columbia University Press.

Billett, S. 2009. "Realising the educational worth of integrating work experiences in higher education." Studies in Higher Education 34, no.7: 827-843.

Commonwealth of Australia. 2015. National Innovation and Science Agenda: welcome to the ideas boom. http://www.innovation.gov.au/system/files/casestudy/National\%20Innovation\%20and\%20Science\%20Agenda\%20-\%20Report.pdf

Curtin, P., and J. Stanwick. 2011. "Overview." In Fostering enterprise: the innovation and skills nexus - research readings, edited by P. Curtin, J. Stanwick and F. Beddie, 10-17. Adelaide, SA: NCVER. 
Dalitz, R., P. Toner and T. Turpin. 2011. VET and the diffusion and implementation of innovation in the mining, solar energy and computer game sectors. Adelaide, SA: NCVER.

Dawe, S. 2004. Vocational education and training and innovation: Research readings. Adelaide, SA: NCVER.

Ellström, P. E. 2010. "Practice-based innovation: a learning perspective." Journal of Workplace Learning, 22: 27-40.

Ernst, D., and L. Kim. 2002. "Global production networks, knowledge diffusion, and local capability formation." Research Policy 31, no. 8: 1417-1429.

Gibson, D., and I. Naquin. 2011. "Investing in innovation to enable global competitiveness: The case of Portugal." Technological Forecasting and Social Change, 78: 1299-1309.

Guile, D., and T. Griffiths. 2001. "Learning through work experience." Journal of Education and Work 14, no. 1: 113-31.

Guthrie, H., E. Smith, S. Burt and P. Every. 2014. Review of the effects of funding approaches on Service Skills qualifications and delivery in Victoria. Melbourne, VIC: Service Skills Australia.

Hodge, S., R. Smith, J. Field and M. Flynn. 2017a. The contribution of VET student placement to innovation in host organisations. Adalide, S.A.: NCVER.

Hodge, S., R. Smith, J. Field and M. Flynn. 2017b. The contribution of VET student placement to innovation in host organisations - Support document. Adalide, S.A.: NCVER.

Hoyrup, S. 2012. "Employee-driven innovation: A new phenomena, concept and mode of innovation." In Employee-driven innovation: A new approach, edited by S. Hoyrup, M. BonnafousBoucher, C. Hasse, M. Lotz and K. Moller, 3-33. Basingstoke: Palgrave Macmillan.

Laursen, K., and A. Salter. 2005. "Open for innovation: the role of openness in explaining innovation performance among UK manufacturing firms." Strategic Management Journal 272: 131-50.

Lazonick, W. 2005. "The innovative firm." In The Oxford handbook of Innovation, edited by J. Fagerberg, D. Mowery and R. Nelson, 29-55. Oxford: Oxford University Press.

Lundvall, B. A. 2008. "Higher education, innovation and economic development." Higher Education and Development: 201-228.

Mincer, J. 1958. "Investment in human capital and personal income distribution." Journal of political economy 66, no. 4: 281-302.

Nelson, R. R., and N. Rosenbereg. 1993. "Technical innovation and national systems." In National Innovation Systems: A Comparative Analysis, edited by R. R. Nelson, 3-22. Oxford: Oxford University Press.

OECD (2005). Oslo Manual: Guidelines for collecting and interpreting innovation data (3 $3^{\text {rd }}$ Ed.). The measurement of scientific and technological activities, Paris: OECD Publishing 
OECD. 2012. Better skills, better jobs, better lives: A strategic approach to skills policy. Paris: OECD Publishing.

OECD. 2015. The innovation imperative: Contributing to productivity, growth and well-being. Paris: OECD Publishing.

Pickersgill, R., and D. Edwards. 2005. "The contribution of VET to innovation in regional industry." In proceedings of the AVETRA 8th Annual Conference, Emerging Futures-Recent, Responsive and Relevant Research, Sofitel, Brisbane, 13-15 April.

Piterou, A., and C. Birch. 2014. "The role of Higher Education Institutions in supporting innovation in SMEs: university-based incubators and student internships as knowledge transfer tools." InImpact: The Journal of Innovation Impact 7, no. 1: 72-79.

Raymond, L., and J. St-Pierre. 2010. "R\&D as a determinant of innovation in manufacturing SMEs: An attempt at empirical clarification." Technovation 30, no. 1: 48-56.

Rice, J. 2011. "Innovation in the modern economy." In Fostering enterprise: the innovation and skills nexus - research readings, edited by P. Curtin, J. Stanwick and F. Beddie. Adelaide, SA: NCVER.

Schumpeter, J. 1934. The theory of economic development: an inquiry into profits, capital, credit, interest and the business cycle. Cambridge, MA: Harvard University Press.

Smith, R. 2017. Three aspects of epistemological agency: The socio-personal construction of work learning. In Agency at Work. Professional and Practice-based Learning, Volume 20, editd by M. Goller and S. Paloniemi. Cham: Springer.

Toner, P. 2007. Skills and innovation - putting ideas to work. Sydney, NSW: Department of Education and Training.

Zulch, D., R. Saunders, J. Peters and J. Quinlivan. 2016. "Effectiveness of a service learning model with Allied Health Assistant students in aged care." International Journal of Training Research 14, no. 2: $161-170$. 